\title{
Dual Character of Contemporary Arts and Ceramic Education
}

\author{
Guanghui Chen \\ Shanghai Academy of Fine Arts \\ Shanghai University \\ Shanghai, China
}

\begin{abstract}
There are big gaps now being encountering with present Chinese contemporary ceramics, from within our ceramic art education system, although they were nearly synonymous in past decades. Along with present Chinese ceramic movements, these gaps have enlarged, creating dramatic changes. Today, what we call this gap, is the word of misunderstanding, especially in contemporary Chinese ceramics is the link between the education system and present art. This meaningful word covers a wide range of cultural background, craft history, and teaching systems, even questioning who owns contemporary ideas from West to East. Finding and understanding this gap will help us criticize and improve our education system.
\end{abstract}

Keywords-contemporary ceramic arts; ceramic education; comparative culture

\section{INTRODUCTION}

Since 20 years ago when the Shanghai Academy of Fine Arts established the ceramics studio until now, it is gradually becoming the currently relatively complete facility and education system from the original blank major setting. During this period, there is lots of hard work which even holds up the creation, but there also comes along plenty of happiness and experience. Much of that cannot be experienced as a pure artist and teacher. As for me, my Chinese and Western education backgrounds and the unique bridge status of Shanghai make the positioning for experimental ceramics studio full of challenges. The positioning of education of experimental ceramics studio is to get away from the Chinese traditional ceramic education mode. It not only adopts traditional teaching method but also expands the ceramic language and materials with the acknowledgement of humanity and participation in contemporary art through setting up the postgraduate and research-based teaching system. It should be mentioned that many experiences in the past these year is what many other art academies have deeply touched or will touch.

The development of Chinese contemporary ceramic education is rapid but far less rapid than the development of contemporary ceramic arts. The indivisible cultural relation between ceramics and China that we all know also makes Chinese contemporary ceramic not only relate to students but also relate to the future trend of Chinese ceramic art. The Chinese ceramics not only provides a kind of material to the world, actually Chinese ceramics is the cultural history of anthropology. This background of anthropology make the ceramics span the ceramic material to enter into the field of cultural construction. It not only constructs the present Chinese culture and aesthetic appreciation, but also participates in the construction of world culture. Therefore, the education of ceramic art is certainly not the technical and pure aesthetic appreciation education, but needs to introduce more macroscopic culturology background and thoughts about contemporary culture. In such background can the success of ceramic art education be logically realized. Sure, it needs a process from quantitative change to qualitative change. From my own teaching experience, there are certain embarrassments between Chinese contemporary ceramic art education and our ideals (although many of them are recessive).

\section{EMBARRASSMENT OF TEACHING SYSTEM}

1-1: Currently, the ceramic art major setting in most of Chinese art academies is still fixed major setting, in other words, the students need to determine the major when they take university entrance examination and once they are admitted by a certain major, they almost cannot change their majors. The teaching program or teaching objectives will make students indiscriminately be positioned as certain major upon enrollment which is actually a kind of thought extension of strongly planned economy. Because there is large contingency in the major selected by students before entrance to university or they cannot accomplish truly deep consideration and there will be students of other majors hoping to transfer to the ceramic art major for learning during university period, if the major is determined before entrance, once the students enter the university, the individual will no longer exit and the students will belong to certain fixed class or major until graduation and the students will almost have no freedom of selection. Of course, the setting of such courses and majors is not specially aiming at the ceramic art but is caused by the systematicness and favorable management of most universities. But as for the ceramic art, the over rigescent major selection does cause the learning initiative of students to be low.

1-2 in the setting of courses of ceramic art major, the setting ratio of drawing foundation is far larger than that of learning and study of ceramic materials and the concern on specific technicality is far more than the requirement on abstract creativity. Although the students are in the contemporary era and are required by the nature of 
contemporary works during creation, there is few or almost no discussion on contemporary art or contemporary artistic phenomenon in course setting. Such asymmetric course setting will result the text logical mess in the artistic concepts and nouns used by students in graduation works and papers.

If one is familiar with current ceramic art teaching structures of China, Japan and America, one can find that such teaching structure will have lots of similar points with the mainstream ceramic art from various countries. Of course, the Chinese ceramic art education possesses its unique advantages. And the natural ceramics, especially the history and humanity of ceramics will ensure the students to imperceptibly receive well edification in the growth environment who may enter the field of aesthetic appreciation and fabrication of ceramics even without too much thinking. However, the favorable conditions at sometime will become certain limitations: (1) the Chinese artistic education techniques focus much on the materials where the utility is much more important than the games; while what is most important in the contemporary ceramic art education is the materials and relaxation of mentality. (2) The Chinese ceramic art education is mostly divided into design or sculpture while the most contents in contemporary ceramic art are independent from above two kinds which should be within the space between both of them but must possess independent aesthetic language. (3) The setting of courses of ceramic art is much too single which will make the work creation modes of students over similar and basically have no setting of courses about contemporary art and contemporary ceramic art phenomenon; while the Intervention of such contents is the reason why ceramic art is called the contemporary ceramic art.

As far as the overall education of ceramic art major or the cultivation of ceramists, it surely is a social problem. But the university education is no doubt very important. In fact, the undergraduates in Chinese academy of arts, especially the freshmen are not weaker than those in Japan and America and may be better on certain degree. However, with the increase of grade until senior, especially during the phase of postgraduate, compared with the qualitative changes produced in the works during senior or postgraduate phases of American students, it may be found that the works of our students have not been improved with the increase of age and experience which are the certain problems in education procedures to a great extent. At least, so far the education of Chinese contemporary ceramic art mostly depends on the personnel comprehension and the education itself or the course setting seem to be complete but cannot change the teacher and course structure or just change the course name into very original names which is is actually a change in form but not in content. And many courses are just course names. Therefore, the ceramic art education, especially the education of contemporary ceramic art is not about how to conduct ceramic art education but about how to reasonably and intelligently adjust the system of Chinese art education on the macro level.

\section{EMBARRASSMENT IN CULTURAL BACKGROUND}

The contemporary ceramic art education is facing to students. And the special Chinese cultural background causes the focus and sensitivity on techniques and perfectness of Chinese ceramic art education to be larger than that on materials or life. At most times, the techniques and perfectness even become the only standard. From the perspective of fabricators, excessive pursuit of techniques or perfect techniques will be abandoned by Chinese scholar's culture and become the handicraft beyond the mainstream scholar's culture when reaching such techniques. From the perspective of appreciators, the techniques and perfect glazing colors will make it over close to the standards for industrial products and even not much different which make the development of Chinese ceramic art in an embarrassing state. While the ceramic painting will relief such embarrassment from another perspective due to its creation flexibility. (Although we need more chapters to discuss ceramic painting, the very Chinesestyle art form).

Of course, ceramic art is a very interesting phenomenon in Chinese cultural history which is impacted by Confucian culture. The ceramic fabricators are essentially exiting as craftsmen in Chinese traditional culture because the Chinese artists who can be directly called scholars disdain to do physical creation. The period from Tang Dynasty to Ming Dynasty is the mature period of Chinese culture and, of course, the formative period of ceramics culture as cultural language. Except for the aesthetic orientation, the scholar artists by no means directly participate in the process of ceramic fabrication while the Chinese scholars like jade because it is symbolized as a kind of quality and cultivation. Therefore, the pursue of Chinese ceramic is intensified because of the many similarities between porcelain quality and jade quality. The Chinese ceramic is much more presented to the public through the perfectness in styles and smooth glazing colors, the intricate decoration techniques and fashion schemes. This is on the contrary with Japanese ceramic phenomenon. The formation of Japanese culture has the direct relations with large quantity introduction of Chinese culture in Tang and Song dynasties while such kind of introduction possesses agricultural and technological manual labor except for religion, system and consciousness. When Japanese learn Chinese culture, they also accept the impacts from Chinese Confucian culture, Taoism culture and Buddhist culture. In fact, the perfect Japanese porcelain was successfully fired in Imari because of the finding of kaolin in late 17th century. From mastering of ceramic techniques to the appearance of ceramic whiteware in Japan, there are hundreds of years during this period to ensure the Japanese fabricators who are also the appreciators to bring every procedure of ceramic fabrication into aesthetic appreciation of works including mud fabrication, molding and firing which guarantees the ceramists to have sufficient time during fabrication and application periods to develop the aesthetic tendency of respecting the natural materials in Japan. This surely is related to the late discovery of kaolin in Japan but what matters more is that there is obvious branches in Japanese culture hundreds years before discovery of Kaolin that means that the social composition is Confucian culture while the culture and living are Taoist culture. I think that using a living example for contrast will be more vivid. Compared with that I use large length to introduce the contemporary American ceramic art phenomenon in another paper, the relations between Chinese ceramists and ceramics is like the father-son relation in traditional sense which means that the ceramists change materials and try to manifest the 
perfect form of such changes as far as possible and they are more interested in the perfectness of results and pursuit sense of order so as to change the non-perfect part in pure nature. And their pursuit of complex craft and techniques are larger than that of artist language extension. The relation between Japanese ceramists and ceramics completely respect the language of the other. The works are created under such mentality from moulding by throwing to firing, mud fabrication as well as glaze fabrication. What is different from the aestheticism in China is that the Japanese ceramics are more like a kind of purely natural and purely material, although you can find many and very complex firing procedures and process in it. The relation between American ceramists and ceramics is more like a kind of friendship which is concentrated to an interesting topic from discussion with no topic along with the interest points of both of them. Therefore, the American ceramics is more like a kind of process and participation. Compared with the Chinese techniques and aestheticism or the Japanese pure nature and pure material, the description of American ceramics is more like a kind of interchangeable process which means that the language of material and creation of artists is the product from joint collision.

\section{EMBARRASSMENT OF EMPLOYMENT SYSTEM}

This is actually the extension of education system. As a kind of art language, the ceramic art is actually misunderstood in many Chinese art academies and it is misunderstood into a industrial language. Once it is misunderstood into a industrial language, all the course setting are circling with this industrial technique development and industrial characteristics. This will result in that all the pure technical knowledge learned will almost loss applications unless the students are engaged in this special industry which will be a huge loss of resources no matter to the students, the state or the teachers. For the students, the prosperity of ceramic industry is not the goal. The students think more from individual perspective to obtain materials as far as possible and contact the sense of beauty of materials which will make students bring the sense of beauty of materials into future creations, although such kinds of creation are possibly not in ceramic materials

\section{EMBARRASSMENT OF CULTURAL DISCOURSE}

In any period, there will be a relatively mainstream value standard. Europe and America possess comprehensive value impact in the world which also makes the contemporary art developed from Europe and America become a kind of mainstream discourse. This kind of mainstream disclosure will have certain supplement to the Chinese traditional ceramic language when being reflected into ceramics but may also possibly conflict with Chinese aesthetical standards. The Chinese culture or Chinese ceramics are actually a kind of introspective culture which has lasted for over thousands of years, is a kind of elegant peace and technical perfectness and focuses much more on the glaze but not the mud and focuses much more on painting but not perfect form. Although the Chinese ceramics impacts the whole world, the contemporary ceramics would rather be said to be ceramics than be said to be contemporary art which will be more suitable. It cannot be said that there is completely no reflection of original Chinese ceramics impact but it has been weakened, instead there are various possibilities of material participating in the contemporary art. Such possibilities are comprehensive, outgoing and swanking diversification which focuses much more on the sensitivity and individualization of personal emotions, focuses on the process not the results and focuses on the materials instead of techniques. As for today, the combination of contemporary ceramics in the world and traditional ceramics begin to become less and less.

\section{EMBARRASSMENT OF CRAFT TRADITION}

In Chinese culture, the culture and handicraft culture are always entirely different systems in a relatively stable social culture system. The scholars focus on philosophy while the handicraftsman focus on techniques. The scholar system is used to guide and evaluate the handcraft while the handicraftsman doesn't really have much speaking right. The value of handcraft is how many techniques that have been mastered, especially those other people do not have. This is a very special value chain in China. The scholar cultivation focuses on "the Flawless". Actually, there are fewer chances for scholars to contact the materials while such flawless judgment system culture makes all the efforts of handicraftsman circle around the range of how to produce flawless techniques. In Europe, America and Japan, due to the large quantity of industrialization and the history of industrial civilization, even the status of handicraftsman is not high; they can still participate in the aesthetic appreciation of ceramics. Or to say that there are no too big differences between scholar culture and handcraft culture, therefore under the general background, the feature of over technicalization of Chinese ceramics makes contemporary artists stay at a respectful distance from such materials and at the same time is abandoned to the secondary mainstream of handcraft. It seems that at most of times, we are using the word "ceramics" at the same time, but the understandings or descriptions from different backgrounds or different people may possess tremendous differences.

\section{CONCLUSION}

The above contents may be written in a rush. There are lots of points needing attention in the Chinese contemporary ceramic art or ceramic art education. From the perspective of art, it will be difficult to determining the advantages or disadvantages, because such aspects can be mutually converted Of course, the above contents are only for reference. There are still many aspects that the author has not given thoughts about or has insufficient attention on. No matter how, the ceramic education of Chinese ceramic art will always be a meaningful matter that needs to be focused. The independent thinking capacity and creative thinking are the orientation which is in urgent need of coordination in our ceramic art education. The establishment and coordination of one education system cannot be accomplished in a short period and the effects cannot be seen within a short period. But once we can see the effects, some things may have lots of changes. The problems arising from the participation in living, construction and other kinds of creations of ceramic art have great relations with 
changes in art education system. How to solve such problems in the process of Chinese ceramic art education is much more important than how to solve many surface technical problems to a great extent, because from the perspective of art, the creation is far more important than techniques. The above contents are the thoughts apart from teaching. If they can induce the thinking of people in the same field or interested people or even induce their criticism, it will be found meaningful in some sense.

\section{REFERENCES}

[1] Introduction to Phobosophy きだげん (Japan) Translated by Lu Xiuping, CITIC Press, 2011 《反哲学入门》木田元（日）陆秀丽 译, 中信出版社, 2011

[2] Japanese Ceramic Art, Zheng Ning, Heilongiiang Fine Arts Press, 2001 《日本陶艺》郑宁, 黑龙江美术出版社, 2001

[3] Contemporary Ceramic Art Education, He Bingqin, Wuhan University of Technology Press, 2005 《现代陶艺教学》何炳钦, 武汉理工大学 出版社, 2005

[4] Symmetry of Islam Geometric Modelling, Abbas (Britain), Translated by Cui Zhongzhou, etc, Ningxia people's Publishing House, 2016 《伊 斯兰几何模式的对称》 阿巴斯 (英), 崔忠州等译 宁夏人民出版 社 2016 